Psychology of Language and Communication 2017, Vol. 21, No. 1

DE GRUYTER

OPEN

DOI: $10.1515 /$ plc-2017-0008

MARTYNA SEKULAK, JÓZEF MACIUSZEK

Jagiellonian University, Cracow

\title{
METAPHORICAL ASSOCIATION BETWEEN PHYSICAL AND MORAL PURITY IN THE CONTEXT OF ONE'S OWN TRANSGRESSIONS AND IMMORAL BEHAVIOR OF OTHERS
}

The Macbeth effect is a metaphorical association between physical and moral cleanliness - transgression of one's morality leads to increased desire to clean oneself (Zhong \& Liljenquist, 2006). Earlier studies examined psychological associations between bodily and moral purity according to controlled processes, such as rating product desirability. The influence of the Macbeth effect on more automatic processes (stimuli processing speed) was explored in three studies. We examined whether thinking about one's moral transgression (Studies 1 and 3) or others' immoral behavior (Study 2) contributed to slower reaction times (RTs) to stimuli related to physical purification. It seems that automatic processes may also be affected by the metaphor "morality is purity": It is manifested in slower RTs to stimuli associated with bodily cleansing when recalling one's own past transgressions (Study 3) and in slower responses to words connected with purification of the external world while recalling immoral behaviors of others (Study 2).

Key words: moral purity, bodily purity, immoral behavior, metaphor

\section{Introduction}

Our everyday language is full of metaphors - we use them so widely and commonly that we are often unaware of the fact that we communicate by them (Lakoff \& Johnson, 1980). Not only does it make speech more aesthetically appealing, but it also (or even primarily) helps us to talk and think about concepts that are difficult to verbalize in a simple way (Lakoff \& Johnson, 1980; Maciuszek, 2004). One of the metaphors that is very deeply ingrained in our

Address for correspondence: Martyna Sekulak, Jagiellonian University, Institute of Applied Psychology, Łojasiewicza 4, 30-348 Kraków, Poland. E-mail: sekulak@wp.pl 
language and thinking is the metaphor "morality is purity" - we associate sin with dirt (e.g. being defiled by a sin) and integrity with cleanliness (e.g. being cleared of charges). How can this metaphor affect our everyday life? Research shows that the metaphorical association between moral and physical purity may influence our understanding of morality in general, as well as of physical experiences, more broadly speaking. There is a phenomenon called the Macbeth effect (Zhong \& Liljenquist, 2006), whereby the feeling of moral threat leads one to feel an increased desire to clean oneself, similarly to Lady Macbeth's desperate attempts to restore her morality by cleaning, or purifying, her hands. This observation seems to be consistent with the cognitive theory of metaphor developed by Lakoff and Johnson (1980). The aim of this paper is to explore how the metaphorical association between moral and physical purity affects automatic processes (processing speed) not only when thinking about one's own moral transgressions but also when thinking about the immoral actions of others.

Lakoff and Johnson's (1980) cognitive theory of metaphor explains the role of metaphors in our attempts to understand difficult and abstract concepts, such as morality. According to Lakoff and Johnson, metaphors are strongly connected with both thinking and acting - and their relation with language is secondary. These authors claim that metaphorical concepts are based on our everyday experiences - their structure is mainly derived from human interactions with the physical world, and they allow us to describe ideas that are beyond simple comprehension. On the other hand, because the role of metaphor is to highlight some features while ignoring others, such a conceptualization determines the way we understand these ideas (Lakoff \& Johnson, 1980, 2010). For example, we usually associate positive or desirable things with up (e.g. "things are looking up"), and bad or negative things with down (e.g. "to look down"). The metaphorical statement that "honesty and morality is up" in society asserts that it is good to live in harmony with others and to respect the society's system of values, because it is beneficial for the group as a unit (Lakoff \& Johnson, 2010). Similarly, our own physical experiences with the world underscore how important it is for our health that we care about purity and thus protect ourselves from contamination and germs. This is why purity is thought of as something good, and why it has become the basis for developing the metaphor "morality is purity" (Haidt, 2001; Lakoff \& Johnson, 2010).

Society is concerned with morality and, presuming Lakoff and Johnson's (1980) main argument is correct, this metaphor enables society to consistently frame the desirable attitudes of its members. The role of morality is to bind and build - morality limits the individuality of people in order to group them and create new units with different features (Durkheim, 1912/1976). From an evolutionary standpoint, groups care about morality because it enables them to solve problems related to cooperation and commitment (Frank, 1988) and, as a result, to fulfill the need for social unity and cohesion (Haidt, 2001, 2007). One's moral transgressions can bring about the feeling of disgust and can 
be treated by other members of society as a threat to the group's morality and purity (similar to the spread of contamination or of an infection). It is for this reason that the group may aim to purify itself by excluding such an immoral member (Rai \& Fiske, 2011) or by symbolic "cleaning" via the process of punishment (Świątnicki \& Przybyszewski, 2014). Because people often draw connections between actions related to biological hygiene and actions related to morality (Zhong, Strejcek, \& Sivanthan, 2010), conceptualizations of morality in terms of purity can be used in wider social propaganda. Associating opponents with impurity or disease may lead people to feel disgust towards them and, thus, an increased need for distance from the source of these feelings. Taken to an extreme, such distancing from social sources of moral impurity can justify even horrific acts against one's opponents, such as ethnic cleansing (Smith, 2011). Experimentally induced disgust has been found to lead to increased distancing from foreign ethnic groups (Sinacka-Kubik, 2011). Morality can help fulfill societal needs, even if they themselves may sometimes seem to be morally impure. The metaphorical conceptualization of morality allows this otherwise abstract concept to be effectively enacted on the path to societal goals.

\section{Macbeth Effect}

According to Lakoff and Johnson's (1980) theory, not only does the metaphor "morality is purity" influence one's understanding of the term morality, but it also influences both our perception and physical experiences. There is a metaphorical association between physical and moral purity that is called the Macbeth effect - whereby one's moral transgression leads to an increased desire to clean oneself, and the act of cleansing correspondingly reduces the unpleasant feelings triggered by the encounter with immorality (Zhong \& Liljenquist, 2006). In Zhong and Liljenquist's (2006) experiment, recalling one's past immoral behavior contributed, for example, to the preference of antiseptic wipes (over pencils) as a gift for participation in the experiment. A person whose moral identity is threatened aims at reducing this feeling of threat by engaging in an activity that allows them to restore their self-esteem, for example, by donating to charity (Sachdeva, Iliev, \& Medin, 2009). When one thinks about an unethical act, one's self of their own moral integrity may also be restored by physical cleansing (Zhong \& Liljenquist, 2006). This cleansing appears to be a form of moral self-regulation - participants who had had a chance to clean their hands after recalling an immoral act were less likely to volunteer in an extra experiment conducted by a desperate student (in comparison to those who had no opportunity to clean their hands). What is more, moral disgust may lead to spontaneous behavior connected with cleansing (Parzuchowski, Bocian, $\&$ Baryła, 2012). In this experiment, students attending a lecture experienced the activation of one of three concepts; either a pedophile, a secretary, or a monk. Relative to the other two groups, more people in the group in which the pedophile stereotype had been activated went directly to the toilet after the lecture had 
finished. Parzuchowski et al. (2012) understood this behavior to be the result of an increased desire to clean oneself (triggered by moral disgust). What is more, the embodiment of moral purity may be specific to the part of the body engaged in the immoral behavior, something that is consistent with phrases used in our everyday language, such as when we say that someone has dirty hands or a dirty mouth (Lee \& Schwarz, 2010, 2011). In Lee and Schwarz's experiment (2010), participants pretended that they were lying via an e-mail message (engaging their hands typing) or via a telephone call (engaging their mouths speaking) after which they were asked to declare their desire for products included on a given list. The participants who had lied by writing a message expressed a greater desire for products associated with the cleaning of one's hands, while those participants who had told lies over the telephone declared a greater desire for products used to clean one's mouth. While there is considerable experimental support for the existence of the metaphorical association between physical and moral purity, some studies failed to find such a relationship. Fayard, Bassi, Bernstein, and Roberts (2009) conducted two studies exploring the Macbeth effect, in which they attempted to replicate Zhong and Liljenquist's (2006) experiments, however, there were no significant differences in gift preferences (an antiseptic wipe vs. a pencil) between the ethical and unethical groups. Similarly, the act of cleansing one's hands did not contribute to a reduced willingness to voluntarily take part in an extra experiment. In sum, Fayard et al. (2009) failed to find support for the claim that an increase of negative moral emotions leads to an intensified need for physical cleansing.

\section{The Influence of the Metaphor "Morality is Purity" on Moral Judgments}

Moral judgments have an influence on our tendencies to punish other people and on our decisions regarding who should be avoided and who can be accepted (Wojciszke, 2014). Are these judgments always intentional and based on careful analysis? Haidt's social intuitionist model $(2001,2007)$ shows that moral judgment is mainly determined by rapid, automatic processes related to moral intuition, something that is strongly connected with a simple sense of good and bad and is based on the metaphor "morality is purity." Rational reasoning, which is an effortful, slow, and controlled process, usually appears as a post hoc justification for the first, intuitively determined decision (Haidt, 2001, 2007). This indicates that our judgments may be influenced by unconscious or incidental stimuli and be subsequently strengthened by moral reasoning. For example, the activation of the concept of physical purity may contribute to less severe moral judgments. Schnall, Benton, and Harvey (2008) found that when the general idea of purity was primed, people judged others more liberally and found their moral transgressions to be less wrong. However, others have found that increasing one's own cleanliness is associated with perceiving oneself as being honest and moral, leading one to give harsher judgments on various social issues (Zhong et al., 2010). Having found the empirical support for Haidt's 
model, Schnall, Benton et al. (2008) claim that the concept of purity serves as the basis for the intuitive component of moral judgments. Haidt (2007) highlights that although automatic processes initiate moral decisions, they do not totally dominate them; the judgment may be influenced by more effortful and controlled processes, but ones that require proper conditions and motivation.

Disgust is an emotion strongly identified with the field of morality. In general, the words disgusting and immoral are used synonymously (Rozin, Haidt, \& McCauley, 2005). What is its role in the formulation of moral opinions? Disgust is a kind of moral emotion - an experience of favorableness or repulsion appearing when a behavior is being morally judged (Dziarnowska $\&$ Przybysz, 2011). Although it is unclear whether or not moral emotions influence the judgment (Dziarnowska \& Przybysz, 2011; Haidt, 2001, 2007) or if they are the result of moral evaluations (Chapman \& Anderson, 2011), there is no doubt that emotions are important in the field of morality and that they are strongly connected with the motivation to engage in specific actions (Huebner, Dweyer, \& Hauser, 2008). Moral disgust has been derived from physical disgust (appearing as a result of consuming toxic substances), and both are accompanied by a similar reaction of facial muscles (Chapman, Kim, Susskind, \& Anderson, 2009), leading to the supposition that they may have been merged. Disgust is evolutionarily aimed at protecting the person from physical danger and it seems that its role has spread to the social field, that is, morality (Rozin et al., 2005). Experiencing physical disgust (e.g. consuming a bitter drink) might contribute to more severe judgments (Schnall, Haidt, Clore, Jordan, 2008), especially when the person doing the judging holds conservative views (Eskine, Kacinik, \& Prinz, 2011). These strict opinions may be assuaged by the act of cleansing (Schnall, Benton et al., 2008). On the other hand, the experience of purity (e.g. sitting in a room filled with a fresh scent) can make a person act more reciprocally and generously (Liljenquist, Zhong, \& Galinsky, 2010).

There are numerous, multifaceted implications that can be drawn from the metaphorical association between morality and purity reported in the experimental and theoretical literature. This connection appears in different areas of human existence - from simple physical sensations to social activity and decision-making. Previous studies have mainly focused on the influence of the Macbeth effect on one's declared desire to own products related to cleansing (e.g. Zhong \& Liljenquist, 2006) or on intentional behaviors connected with purifying (Parzuchowski et al., 2012). In the current research, we explore the metaphorical conceptualization of morality in the context of less controlled processes. With the help of a lexical decision task (LDT), we examine how quickly people, having thought about immorality/morality, respond to stimuli associated with physical cleansing. The general purpose of the LDT is to quickly classify letter sequences appearing on the screen into two categories - words (meaningful in the given language) and nonwords (meaningless blends of random letters). This task measures how quickly participants categorize the presented 
stimuli. The LDT is based on the assumption that on the grounds of simple reactions to a word's cognition, it is possible to presume the level of memory accessibility of certain concepts; the reaction time (RT) to the stimuli is treated as the rate of activation of a particular mental representation (Bukowski, 2008). According to the model of semantic networks, the stimulation of one concept contributes to the activation of concepts linked to it (Collins \& Loftus, 1975). As a consequence of such linkages, the LDT leads to quicker recognition of words with semantically associated meanings (Bukowski, 2008). Generally, the LDT is used in experiments to explore how the priming of certain ideas and concepts influences the RT to various stimuli - with an expectation that quicker responses to the stimuli are triggered by the activated category. However, some research has found that the stimulation of a certain mindset may lead to the inhibition of stereotypical associations (Sassenberg \& Moskowitz, 2005). We presumed that, in situations of morality threats, people doing the LDT will pay more attention to words related to cleansing. Due to the fact that intentionally focusing attention on detected stimuli leads to slower RTs (Maciuszek, 2007, 2013), we predicted that, when primed with an immoral action, we will see a delay in RTs to phrases associated with purifying in the LDT. In this way, we tested whether thinking about one's own moral transgressions results in slower RTs to words connected with body cleansing while thinking about the moral transgressions of someone else results in slower RTs to stimuli related to purifying the external world.

\section{Study 1}

The Macbeth effect is connected with an increased desire to clean one's body (Zhong \& Liljenquist, 2006), especially that part of the body that was involved in the unethical act (Lee \& Schwarz, 2010, 2011). For this reason, we predicted that in the LDT, participants in the immoral condition will exhibit slower RTs only to words connected with body cleansing (in comparison to neutral ones) and that this effect will not generalize to concepts that are not relevant to bodily purification (e.g. the purification of the external world). Additionally, we expected that there would be no difference in RTs to neutral words and to words related to cleansing when participants were asked to think about one's own moral integrity.

\section{Method}

Participants. Sixty male Polish students and graduate students at the Jagiellonian University voluntarily participated in the experiment $\left(M_{\text {age }}=22.8\right.$ years $)$. Each participant was individually approached on campus by the experimenter and asked to take part in the research.

Materials. A computer task based on the LDT was used. In order to check how quickly participants respond to certain words, we used a computer program which measures RTs. Using the right and left CTRL keys on the keyboard, participants were asked to classify the black letter sequences appearing in 
the center of a white screen into two categories - words (meaningful in the Polish language) and nonwords. The left CTRL key was pressed when a meaningful word on the screen was recognized, while the right CTRL key was used in the case of a meaningless letter combination. During the LDT procedure, the categories were constantly presented in the top left ("WORD") and top right ("NONWORD") corners of the screen in order to prevent people from mistaking the sides of the keyboard with which the categories were matched. If a participant made a mistake, a warning written in red appeared in the center of the screen ("MISTAKE") and the participant then had to correct the answer. The program registered the RT to every stimulus, including both correct and incorrect responses. Among the presented letter combinations, there were three words related to body cleansing (soap, shower, and bath), three words associated with cleaning the external world (broomstick, vacuum, and cloth) and six neutral words (noun, garden, chair, curve, step, and work). The 12 remaining letter combinations were meaningless in the Polish language. In a pilot test, we found no significant differences in RTs to the neutral words and to the words connected with purity. There were also no differences between men and women in the RTs to these stimuli.

Placing a word in the context of other words may contribute to the facilitation or inhibition of particular concepts and as a result, it may influence the RT to the stimulus (Bukowski, 2008). Taking this issue into consideration, the order in which the stimuli were presented in the experiment was arranged in such a way so as to avoid priming effects; phrases with related meanings did not appear straight after each other. Moreover, in order to avoid the influence of practice effects on the final results, there were three versions of the order in which the letter combinations might have appeared. One of these three task versions was randomly assigned to each participant. In the pilot study, there were no significant differences in RTs to the words presented in these three different sequences.

Procedure. The volunteers were randomly assigned to one of two conditions (30 people per condition) - ethical and unethical. In the latter group, participants were asked to think about their hypothetical immoral attitude while in the former group, people were made to think about their morality. The experiment took place in the library of the Faculty of Management and Social Communication at the Jagiellonian University. Each participant was taken to one of the rooms dedicated to individual work. The room was equipped with a desk, two chairs, and a computer. People entered the room individually, sat in front of the computer, and were briefed on the procedure. They were told that the experiment is related to the field of social communication.

The whole experimental procedure took about 5-10 min and consisted of three parts. First, all of the participants were provided with the trial series of the LDT. Before starting, participants were informed that quick and correct responses are desirable. Only neutral words (i.e., meaningless nonwords and those not related to physical purity) were included in this series. Having finished 
the task, participants were given a piece of paper with the instruction to imagine a situation in which they managed to avoid unpleasant consequences of their behavior due to the fact that their best friend had borne full responsibility for their act (unethical condition) or to imagine a situation in which their best friend managed to avoid the unpleasant consequences of his or her behavior thanks to the participant's help (ethical condition). In both conditions, people were asked to write down all their thoughts, feelings, and acts associated with the imagined situation. It was stressed that the piece of paper and the notes were helpful for imagining the situation and that the notes would not be seen by the experimenter because they were not the main subject of research and that they would not be included in the analyses. Each volunteer could take the notes with them after the procedure had been finished. There was no time limit for doing this task and participants were told to inform the researcher when they had finished. In the last part of the procedure, participants were presented with the primary series of the LDT, including words associated with physical purity (related to the body and the external world), neutral words, and nonwords.

\section{Results}

Reaction times to words connected with purity of the body were not statistically different between the ethical and unethical conditions $F(1,58)=0.32 ; p=.58$. There was also no significant difference between these two conditions in the RTs to words connected with purity of the external world $F(1,58)=0.00 ; p=.94$.

Table 1. Mean RTs and Standard Errors (SD) for Words Connected with Purity of the Body, Purity of the External World, and Neutral Words, in Both Ethical and Unethical Conditions

\begin{tabular}{llcc}
\hline \multirow{2}{*}{ Condition } & \multicolumn{1}{c}{ Word category } & \multicolumn{2}{c}{ Reaction times (ms) } \\
& & $\boldsymbol{M}$ & $\boldsymbol{S D}$ \\
\hline \multirow{2}{*}{ unethical } & connected with purity of the body & 661.2 & 166.14 \\
& neutral words & 632.5 & 137.01 \\
\multirow{2}{*}{ ethical } & connected with purity of the body & 639.6 & 127.75 \\
& neutral words & 660.1 & 138.03 \\
\multirow{2}{*}{ unethical } & connected with purity of the external world & 696.1 & 178.22 \\
& neutral words & 657.9 & 137.34 \\
\multirow{2}{*}{ ethical } & connected with purity of the external world & 692.5 & 184.72 \\
& neutral words & 657.9 & 137.31 \\
\hline
\end{tabular}

None of the comparisons in the unethical condition showed significant differences. RTs to words connected with purity of the body did not significantly differ from either neutral words or words connected with purity of the external world. There was also no difference in RTs to words connected with purity of the external world and to neutral words. In the ethical condition, there 
was no significant difference in RTs between words connected with purity of the body and neutral words, nor was there a significant difference between words connected with purity of the external world and neutral words.

\section{Discussion}

In Study 1, when participants thought about their own immoral action, we found no significant differences in RTs to stimuli connected with cleansing. Thus, we failed to find support for the claim that morality threats are associated with slower RTs to words related to body cleansing. We speculated that the manipulation was not strong enough to trigger the anticipated effect; imagining a hypothetical behavior does not lead to a delay in RTs. Although no significant effects were found in Study 1, there was an interesting pattern in the ethical group: When participants imagined helping a friend to avoid the unpleasant consequences of their behavior, participant RTs to words related to cleaning the external world were slower than RTs to neutral words. We realize that the instructions did not lead participants to think only about their own moral behavior but also about the immoral behavior of their friend. Having reanalyzed Zhong and Liljenquist's (2006) findings, Lee and Schwarz (2010) suggest that thinking about the immorality of others is related to an increased desire to clean the external world, rather than to the desire to purify one's own body. We speculated that the instructions were not clear enough in this regard and, as a result, when imagined that they were helping a friend, participants focused on the fact that the friend had committed an unethical act.

\section{Study 2}

Having taken into consideration the results from Study 1 and the assumptions about a link between morality of others and the purity of external world (Lee \& Schwarz, 2010), we decided to perform a second study in which we directly tested whether thinking about the moral transgressions of others is related to a greater desire to clean the external world. In Study 2, all of the participants were to think about an immoral act committed by someone else. This time, in order to strengthen the effect, we changed the instructions. While in the first experiment people were asked to imagine a hypothetical situation, in the second experiment, they were asked to recall an act of immorality that had actually taken place. Moreover, it was explicitly highlighted in the instructions that the recalled behavior should have contributed to negative emotions on the part of the participant. We predicted that thinking about the immoral behavior of another would result in slower RTs to words associated with cleansing the external world, while it would not influence the RTs to neutral stimuli and phrases connected with purifying the body. 


\section{Method}

Participants. Sixty students ( 30 men and 30 women; $M_{\text {age }}=21.65$ years) at the Jagiellonian University voluntarily took part in the second experiment. As in Study 1, all participants were recruited on the university campus.

Materials. In the second experiment, the same computer task based on the LDT procedure as in the first study was used. Again, it included two series - trial and primary, each of them consisting of stimuli applied in the previous experiment.

Procedure. The procedure lasted 5-10 min and, once again, took place in the library of the Faculty of Management and Social Communication at the Jagiellonian University. Each volunteer individually entered the room (equipped similarly to the room used in Study 1), and was told that the study was related to the field of social communication.

As in Study 1, the procedure consisted of three parts. The first step was the trial series of the LDT. Participants were given the description of the task and were asked to respond correctly and as quickly as possible. In the second part of the procedure, each participant was provided with a piece of paper with the instructions to recall an example of someone else's unethical behavior that was particularly unsettling for the participant. The experimenter suggested that the participants take notes while thinking about this event (regarding their feelings, thoughts, and acts associated with that situation, etc.) as such notes are often helpful in the process of conjuring up a vivid memory. As in Study 1, participants were informed that their notes would neither be read by the experimenter nor included in the analyses. There was no time limit, and participants were asked to inform the experimenter when they had finished the work. In the last step, the procedure was the same as in Study 1: Participants completed the primary series of the LDT.

\section{Results}

Participants responded slower to words connected with purity of the external world relative to both neutral words, $F(1,58)=8.51 ; p<.01$, and to words related to body cleansing, $F(1,58)=8.86 ; p<.01$. Thus, thinking about the immoral behavior of another influenced the time it took participants to classify words connected with cleansing the external world; responses to these words were slower. However, there were no differences in RTs to words connected with purity of the body or to neutral words. 
Table 2. Mean RTs and SDs for Words Connected with Purity of the Body, Purity of the External World and Neutral Words for the Unethical Condition

\begin{tabular}{lcc}
\hline \multirow{2}{*}{ Word category } & \multicolumn{2}{c}{ Reaction times (ms) } \\
& $\boldsymbol{M}$ & $\boldsymbol{S D}$ \\
\hline connected with purity of the body & 675.8 & 175.42 \\
neutral words & 667.7 & 148.71 \\
connected with purity of the external world & 732.5 & 204.13 \\
neutral words & 677.8 & 129.85 \\
\hline
\end{tabular}

\section{Discussion}

We found that recalling an unethical behavior that had actually taken place in the past led to the slowing of RTs to words related to cleansing. From this, we conclude that the metaphorical association between morality and purity may indeed be expressed on a more automatic level. What is more, it appears that this effect may be triggered by thinking about a case of immoral behavior that has actually taken place. Thinking about an immoral act someone else had actually committed resulted in the delay of RTs to words connected with cleansing the external world. This effect did not generalize to stimuli associated with body purification. This seems to be consistent with the results of both Study 1 and Lee and Schwarz's (2010) assertion that the immorality of others is metaphorically linked to the cleansing of the world around us.

\section{Study 3}

In Study 2, recalling a real immoral act resulted in the delay of participant reactions to words related to cleansing. It appears that this effect of the metaphorical association between morality and purity may be triggered by thinking about a genuine situation. In Study 3, we wanted to verify if recalling one's own transgressions from the past would lead to the lengthening of RTs to stimuli related to body purification. Similar to Study 1, people were asked to think about their own immoral or moral behavior but this time, they were asked to recall an actual behavior (instead of an imagined one).

When thinking about an unethical act committed by someone else, participants responded slower to words associated with cleaning the external world. This finding provides further support for our interpretation of the results of Study 1, in which participants in the ethical condition (in which they imagined helping a friend who might have had committed an unethical act), responding to the immoral act of another, also responded slower to words connected with purification of the external world. These results indicate that another's immorality may contribute to our desire to purify the world around us. Nevertheless, there is still the possibility that in Study 1, the observed pattern (not a significant result) 
- slower RTs found in the ethical condition - was also triggered by the activation of one's integrity (something that might have motivated participants to reduce the risk of contamination coming from the outside). In Study 3, we examined this possibility. In one of the conditions, people were asked to recall an actual example of their own ethical behavior from the past. This time, the instructions directly indicated the participant's own moral behavior, thereby reducing the possibility that they focused on the morality of another. We predicted that the priming of one's own past moral behavior would not lead to slower RTs to words related to the cleanliness of the external world.

We assumed that the delay in RTs to cleansing-related stimuli is brought about by the fact that participants are focusing their attention on these stimuli in particular. As such an increased focus of attention is usually associated with better memory for the stimuli in question (Maciuszek, 2007), in Study 3, we also explored the participants' ability to recall those phrases connected with purification used in the LDT. We predicted that having thought about one's immorality would contribute to recalling more cleansing related words in the memory test, relative both to the condition in which people were asked to think about their own integrity and to the control condition.

Finally, in Study 3, in order to examine how people felt after recalling these various situations, participants were provided with a short task in which they ranked how much they were experiencing a number of emotions. Haidt (2003) claims that, among the moral emotions, there are some that are strongly connected with condemnation of other people, such as disgust or anger (triggered by the moral transgression of someone else), and emotions focused on oneself (appearing in response to one's own unethical behavior), for example guilt, shame, and embarrassment. We predicted that recalling one's own immorality from the past would result in an increased activation of those emotions included in the latter group (relative to the control and the ethical conditions).

\section{Method}

Participants. Ninety Polish students of the Jagiellonian University (68 women, 22 men; $M_{\text {age }}=20.52$ years) voluntarily took part in Study 3 . As in Studies 1 and 2, the participants were recruited in person on the university campus.

Materials. Lexical Decision Task. We used the same computer task based on the LDT procedure as in Studies 1 and 2. We included all three versions of the word order in which the letter blends may have appeared, so as to reduce the risk of the serial position effect (the primacy and recency effects) on the results in the memory test.

Emotion rating task. Participants were presented with a paper-and-pencil task in which they were asked the degree to which they were feeling a number of emotions at the present moment. Answers were given on a 5-point Likert scale, from 1 (not at all) to 5 (very much). The list of emotions included both positive 
emotions (pleasure, joy, serenity, excitement) and negative emotions (sadness, guilt, anger, fear, and disgust).

Procedure. Participants were randomly assigned to one of three groups unethical, ethical, or control. The procedure took place in a laboratory room in which six workplaces were prepared. Each workplace was equipped with a desk and a computer, and was separated from the neighboring workplaces by a partition. Participants came to the lab in groups of six. After sitting individually in front of their own computer stations, participants were briefed on the procedure. The procedure lasted 10-15 min and consisted of five steps. First, participants were provided with the trial series of the LDT. The description of the LDT task and the stimuli used were the same as in the previous studies. Participants were then asked to recall a situation from their past that had actually taken place. In the unethical condition, they were asked to think about a moral transgression. In the ethical condition, participants were asked to think about a moral act, while in the control condition, they were asked to think about a time when they had unexpectedly bumped into a friend whom they had not seen for a while. As in Studies 1 and 2, participants had a piece of paper and could take down notes regarding their feelings and thoughts, and they were informed that those notes would not be collected at the end of the study but that they were for their use alone. At this point, the participants took part in the LDT. Participants were then provided with the task, in which they rated how much they were feeling a number of emotions. Finally, participants were given the memory task. Each person was asked to write down as many of the words as they could recall from those they had recognized in the primary series of the LDT.

\section{Results}

First, we tested how the task of recalling one's own ethical or unethical behavior influenced participants' emotional state in both the experimental groups and the control group. Participants in the unethical condition exhibited a significantly higher level of negative emotions than those in the ethical condition $F(1,84)=9.95, p<.01$, and in the control condition, $F(1,84)=10.99, p<.01$. The ethical and control conditions did not differ significantly, $F(1,84)=0.04$, $p=.84$. Positive emotions were lower in the unethical condition than in the ethical one, $F(1,85)=5.28, p<.05$, whereas the difference between the unethical and the control condition did not reach the conventional level of significance, $F(1,85)=3.12, p=.081$. No significant difference was noted between the ethical and control conditions, $F(1,85)=0.26, p=.61$.

A more detailed analysis revealed that in the unethical condition, two emotions - guilt and sadness - were felt most strongly by participants: The average ratings of these two emotions were significantly higher than the averages for the remaining negative emotions, $F(1,84)=20.34, p<.001$. This indicates that recalling one's own improper behavior lowered positive emotions and increased 
negative emotions (especially the feelings of guilt and sadness). In the ethical condition, no significant differences between the emotions were noted.

The key question was whether in the unethical condition, participants reacted slower to the words related to body cleansing than to the neutral words. It turned out that in the unethical condition, participants responded slower to words connected with purity of the body as compared with neutral words, $F(1,86)=3.97, p<.05$. Also, in the ethical condition, the RTs to words related to body cleansing were slower than the RTs to neutral words, but this difference was only marginally significant, $F(1,86)=3.55, p=.06$. In control condition the RTs to words related to purity of body and to neutral words were identical $(F(1,86)=0.003) ; p=.95)$. The RTs to words connected with purity of the external world and to neutral words were not statistically different in either the ethical, $F(1,86)=0.02, p=.89$, or unethical, $F(1,87)=0.01, p=.92$, conditions.

Table 3. Mean RTs and SDs for Words Connected with Purity of the Body for the Ethical, Unethical, and Control Conditions

\begin{tabular}{llcc}
\hline \multirow{2}{*}{ Condition } & Word category & \multicolumn{2}{c}{ Reaction times (ms) } \\
& & $\boldsymbol{M}$ & $\boldsymbol{S D}$ \\
\hline \multirow{2}{*}{ unethical } & connected with purity of the body & 661.5 & 201.92 \\
& neutral words & 622.8 & 152.15 \\
\multirow{2}{*}{ ethical } & connected with purity of the body & 645.8 & 121.93 \\
& neutral words & 609.2 & 79.64 \\
\multirow{2}{*}{ control } & connected with purity of the body & 586.5 & 120.25 \\
& neutral words & 598.0 & 120.21 \\
\hline
\end{tabular}

At the end of the experiment, the participants were asked to write down all of the words from the LDT that they were able to recall. There were no significant differences between the memory of the words related to body cleansing and neutral words in either the unethical condition, $F(1,86)=0.47, p=0.49$, or the ethical condition, $F(1,86)=1.04, p=0.31$. However, in all conditions, participants recalled more words connected with purity of the external world than neutral words $(F(1,86)=7.37, p<.01$ in the unethical condition, and $F(1,86)=9.30, p<.01$ in the ethical condition). In comparison to the control condition, participants remembered fewer words related to body cleansing in unethical condition, $F(1,86)=5.12, p<.05)$, but there were no significant differences in the ethical condition, $F(1,86)=2.22, p=.13$.

\section{Discussion}

We managed to replicate the findings of Study 2, namely, that the effect of the metaphorical association between morality and purity may be expressed on a more automatic level by the slowing of responses to certain stimuli, 
and that this effect may be triggered by thinking about a situation that has actually taken place.

Recalling an immoral action that one has actually committed resulted in the delay of RTs to words connected with body cleansing, but it did not affect the RTs to words related to the purification of the external world (in comparison to the control words). We found that one's morality is associated with the purification of the body, something that is consistent with the results of previous research on the Macbeth effect (e.g. Zhong \& Liljenquist, 2006). On the other hand, we found that thinking about one's integrity did not contribute to the slowing of RTs to words connected with cleansing the external world, thus it seems that the purification of the external world is associated with encountering the immoral actions of others, and not with one's own immoral behavior.

We found that recalling one's moral transgressions is associated with an increase of negative emotions, especially guilt and sadness. Guilt is a selffocused moral emotion that appears when one has committed an immoral act (Haidt, 2003). Consistently with this understanding of guilt, participants who recalled a moral transgression experienced this emotion more strongly. However, the manipulation did not influence the feel of disgust, which is a moral emotion linked with encounters with immoral others (Haidt, 2003).

Finally, the results from the memory test showed that participants remembered fewer words related to body cleansing in the unethical condition (in comparison to the control condition). This is inconsistent with our prediction that thinking about one's immorality improves the recall of stimuli connected with body purification. It seems that such a manipulation inhibited both RTs and recall for such words.

\section{General Discussion}

In three studies, we explored the influence of the metaphorical association between moral purity and physical purity on stimuli processing speed automatic processes. We tested whether one's own moral transgressions are readily associated with purity of the body (Studies 1 and 3), and whether the moral transgressions of others are readily associated with cleansing the external world (Study 2). It seems that automatic processes may also be affected by the metaphor "morality is purity," something that is manifested in slower RTs to stimuli associated with cleansing. We had presumed delayed responses to be the result of an increased focus on words related to purification, but our findings call this into question. It has been reported that increased attention paid to objects results in longer RTs to them, as well as in better recall of them in subsequent memory tests (Maciuszek, 2013). However, the results of Study 3 suggest that thinking about one's own immoral behavior led participants to remember fewer words associated with body cleansing (in comparison to the control condition). We had predicted that in all three 
conditions, people would recall more cleansing-related words (connected with the body and with the external world) than neutral phrases due to the fact that the LDT would have activated the semantic networks of both concepts, thereby making these words more accessible in memory. In every condition, participants recalled more words associated with the purification of the external world, something that most likely indicates the activation of this semantic network by the LDT. Thinking about one's own immoral behavior resulted in a decrease in the number of recalled words related to body cleansing, which suggests that this semantic network might have been inhibited. Perhaps priming the concept of one's immorality impairs the memory of body cleansing-related words? This is an intriguing effect and it would be very interesting to identify exactly what brought it about.

Although we cannot be sure what the exact reason for the longer RTs to this kind of stimuli is, Studies 2 and 3 suggest that it is related to thinking about immorality/morality. Recalling one's own unethical behavior contributed to delayed RTs to stimuli connected with body cleansing, something that is consistent with the results of previous research on the Macbeth effect (e.g. Lee \& Schwarz, 2010, 2011; Parzuchowski et al., 2012; Zhong \& Liljenquist, 2006). Slower RTs to stimuli related to the purity of the external world were registered only when participants were asked to think about the immoral behavior of others. This effect was not found when participants were asked to think about their own moral behavior. We assume that, while one's own morality is strongly associated with bodily purity, the morality of the other people is more closely linked with the cleanliness of the external world, something that is consistent with the predictions of Lee and Schwarz (2010).

From the social point of view, it seems that the purity of the world around us is metaphorically related to the morality of the group and its members. Moral transgressions of group members are a threat to the group's collective morality and are therefore understood as posing the threat of contaminating the rest of the collective body, much like the spread of an infection. In such situations, the transgressor can purify him- or herself on their own (i.e., expressing a desire to literally clean their body - the Macbeth effect), or they may be purified or excluded by others whose desire is to "clean" the space of the group; communal punishments that can lead to metaphoric purification (Świątnicki \& Przybyszewski, 2014) or to social exclusion or isolation (Rai \& Fiske, 2011). All of these acts aim to restore the sense of collective or individual moral selfimage by engaging in metaphorical (or physical) cleansing. Such cleansing also keeps the moral infection from spreading. This may be the reason why acts against opponents conceptualized in terms of cleansing (e.g. ethnic cleansing) are often so easily justified (Smith, 2011). This metaphorical conceptualization causes both a physical and a moral threat of contamination among community members. It seems intriguing whether one can effectively (and intentionally) decrease the influence of this effect on themselves. 
The results of Study 1 suggest that imagining one's own immoral behavior may not be enough to significantly decrease RTs to words related to body cleansing. However, Study 3 found that the recall of past moral transgressions that one actually committed seem to be intense enough to lead to a greater desire to purify oneself. Previous research has shown that induced disgust has to be intense enough so as to influence moral judgments (David \& Olatunji, 2011). Our findings, along with the complementary findings of David and Olatunjui (2011), speak to the fundamentally important role of proper manipulations within experimental research on the effects of metaphorically conceptualized morality.

\section{References}

Bukowski, M. (2008). Zastosowanie paradygmatu decyzji leksykalnych do badania aktywizacji stereotypów [Lexical decision task applications to study stereotype activation]. Psychologia Spoleczna, 1, 54-63.

Chapman, H. A., \& Anderson, A. K. (2011). Varieties of moral emotional experience. Emotion Review, 3, 255-257. doi:10.1177/1754073911402389

Chapman, H. A., Kim, D. A., Susskind, J. M., \& Anderson, A. K. (2009). In bad taste: Evidence for the oral origins of moral disgust. Science, 323, 12221226. doi:10.1126/science. 1165565

Collins, A. M., \& Loftus, E. F. (1975). A spreading activation theory of semantic processing. Psychological Review, 82, 407-428. doi:10.1037/0033295X.82.6.407

David, B., \& Olatunji, B. O. (2011). The effect of disgust conditioning and disgust sensitivity on appraisals of moral transgressions. Personality and Individual Differences, 50, 1142-1146. doi:10.1016/j.paid.2011.02.004

Durkheim, E. (1995). The elementary forms of the religious life. New York, NY: The Free Press (Original work published 1912).

Dziarnowska, W., \& Przybysz, P. (2011). Emocje moralne jako podstawa zmysłu moralnego. Defekty zmystu moralnego [Moral emotions as the basis of moral sensitivity. Defects of moral sensitivity]. Rocznik Kognitywistyczny, 4, 57-64.

Eskine, K. J., Kacinik, N. A., \& Prinz, J. J. (2011). A bad taste in the mouth: Gustatory disgust influences moral judgmant. Psychological Science, 22, 295-299. doi:10.1177/0956797611398497

Fayard, J. V., Bassi, A. K., Bernstein, D. M., \& Roberts, B. W. (2009). Is cleanliness next to godliness? Disspelling old wives' tales: Failure to replicate Zhong and Liljenquist (2006). Journal of Articles in Support of the Null Hypothesis, 6, 21-29.

Frank, R. H. (1988). Passions within reason: The strategic role of the emotions. New York, NY: Norton \& Co. 
Haidt, J. (2001). The emotional dog and its rational tail: A social intuitionist approach to moral judgment. Psychological Review, 108, 814-834. doi:10.1037//0033-295X.108.4.814

Haidt, J. (2003). The moral emotions. In R. J. Davidson, K. R. Scherer, \& H. H. Goldsmith (Eds.), Handbook of affective sciences (pp. 852-870). Oxford: Oxford University Press.

Haidt, J. (2007, May). The new synthesis in moral psychology. Science, 316(5827), 998-1002. doi:10.1126/science.1137651

Huebner, B., Dweyer, S., \& Hauser, M. (2008). The role of emotion in moral psychology. Trends in Cognitive Science, 13, 1-6. doi:10.1016/j. tics.2008.09.006

Lakoff, G., \& Johnson, M. (1980). The metaphorical structure of the human conceptual system. Cognitive Science, 4, 195-208. doi:10.1016/S03640213(80)80017-6

Lakoff, G., \& Johnson, M. (2010). Metafory w naszym życiu [Metaphors we live by.] Warsaw: Aletheia.

Lee, S. W. S., \& Schwarz, N. (2010). Dirty hands and dirty mouths: Embodiment of the moral-purity metaphor is specific to the motor modality involved in moral transgression. Psychological Science, 21, 1423-1425. doi:10.1177/0956797610382788

Lee, S. W. S., \& Schwarz, N. (2011). Wiping the slate clean: Psychological consequences of physical cleaning. Psychological Science, 20, 307-311. doi:10.1177/0963721411422694

Liljenquist, K. Zhong, C. B., \& Galinsky, A. D. (2010). The smell of virtue: Clean scents promote reciprocity and charity. Psychological Science, 21, 381-383. doi:10.1177/0956797610361426

Maciuszek, J. (2004). Metafora jako forma komunikacji perswazyjnej [Metaphor as a form of persuasive communication]. In R. Garpiela, \& K. Leszczyńska (Eds.), Sztuka perswazji. Socjologiczne, psychologiczne i lingwistyczne aspekty komunikowania perswazyjnego [The art of persuasion. Sociological, psychological, and linguistic aspects of persuasive communication] (pp. 115-130). Kraków: NOMOS.

Maciuszek, J. (2007). Wpływ bezpośrednich i zaprzeczonych dyrektyw na ukierunkowanie uwagi [Influence of direct and negated directives on focusing of attention]. Psychologia Spoleczna, 2, 144-163.

Maciuszek, J. (2013). Don’t pay attention to what you see! Negative commands and attention bias. Polish Psychological Bulletin, 44, 70-84. doi:10.2478/ ppb-2013-0008

Parzuchowski, M., Bocian, K., \& Baryła, W. (2012). Aktywizacja stereotypu osoby niemoralnej nasila motyw czystości [Activation of a stereotype of an immoral person facilitates the cleanliness motive]. Psychologia Spoteczna, 4, 297-305. 
Rai, T. S., \& Fiske, A. P.(2011). Moral psychology is relationship regulation: Moral motives for unity, hierarchy, equality, and proportionality. Psychological Review, 118, 57-75. doi:10.1037/a0021867.

Rozin, P., Haidt, J., \& McCauley, C. R. (2005). Wstręt [Disgust]. In M. Lewis \& J. M. Haviland-Jones (Eds.), Psychologia emocji [Psychology of emotion] (pp. 798-819). Gdańsk: GWP.

Sachdeva, S., Iliev, R., \& Medin, D. L. (2009). Sinning saints and saintly sinners. The paradox of moral self-regulation. Psychological Science, 20, 523-528. doi:10.1111/j.1467-9280.2009.02326.x

Sassenberg, K., \& Moskowitz, G. B. (2005). Don’t stereotype, think different! Overcoming automatic stereotype activation by mindset priming. Journal of Experimental Social Psychology, 41, 506-514. doi:10.1016/j. jesp.2004.10.002

Schnall, S., Benton, J., \& Harvey, S. (2008). With a clean conscience: Cleanliness reducestheseverityofmoraljudgments. PsychologicalScience, 19, 1219-1222. doi:10.1111/j.1467-9280.2008.02227.x

Schnall, S., Haidt, J., Clore, G. L., \& Jordan, A. (2008). Disgust as embodied moral judgment. Personality and Social Psychology Bulletin, 34. doi:10961109. 10.1177/0146167208317771

Sinacka-Kubik, E. (2011). Wpływ wstrętu na uprzedzenia etniczne kobiet i mężczyzn [The influence of disgust on ethnic prejudice of women and men]. Psychologia Spoteczna, 1, 24-33.

Smith, D. L. (2011). Najbardziej niebezpieczne ze zwierzq̨. Natura ludzka $i$ przyczyny wojen [The most dangerous animal: Human nature and the origins of war]. Warsaw: Wydawnictwo CiS.

Świątnicki, K., \& Przybyszewski, K. (2014). Przypomnienie o śmierci i fizyczne oczyszczenie się a poparcie idei lustracji [The effects of mortality salience and physical cleansing on support for vetting (or lustration)]. Psychologia Społeczna, 3, 298-310. doi:10.7366/1896180020143003

Wojciszke, B. (2014). Psychologia społeczna [Social psychology]. Warsaw: Wydawnictwo Naukowe Scholar.

Zhong, C. B., \& Liljenquist, K. (2006). Washing away your sins: Threatened morality and physical cleansing. Science, 313, 1451-1452. doi:10.1126/ science. 1130726

Zhong, C. B., Strejcek, B., \& Sivanthan, N. (2010). A clean self harsh moral judgment. Journal of Experimental Social Psychology, 46, 859-862. doi:10.1016/j.jesp.2010.04.003 